\title{
Kalman filter applied to Thevenin's modeling of a lead-acid battery
}

\author{
Jose Alfredo Palacio-Fernández ${ }^{1,2}$, Edwin García Quintero ${ }^{1}$ \\ ${ }^{1}$ TESLA Research Group, Universidad de Antioquia, Medellín, Colombia \\ ${ }^{2}$ GIIAM Research Group, Institución Universitaria Pascual Bravo, Medellín, Colombia
}

\begin{tabular}{l} 
Article Info \\
\hline Article history: \\
Received May 25, 2020 \\
Revised Nov 15, 2021 \\
Accepted Nov 25, 2021 \\
\hline
\end{tabular}

Keywords:

Electric model

Identification

Open circuit voltage

State of charge

\begin{abstract}
This article determines the internal parameters of a battery analyzed from its circuit equivalent, reviewing important information that can help to identify the battery's state of charge (SOC) and its state of health (SOH). Although models that allow the dynamics of different types of batteries to be identified have been developed, few have defined the lead-acid battery model from the analysis of a filtered signal by applying a Kalman filter, particularly taking into account the measurement of noise not just at signal output but also at its input (this is a novelty raised from the experimental). This study proposes a model for lead-acid batteries using tools such as MATLAB ${ }^{\circledR}$ and Simulink ${ }^{\circledR}$. First, a method of filtering the input and output signal is presented, and then a method for identifying parameters from 29 charge states is used for a leadacid battery. Different SOCs are related to different values of open circuit voltage (OCV). Ultimately, improvements in model estimation are shown using a filter that considers system and sensor noise since the modeled and filtered signal is closer to the original signal than the unfiltered modeled signal.
\end{abstract}

This is an open access article under the CC BY-SA license.

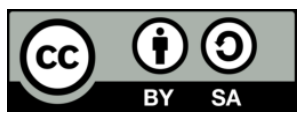

\section{Corresponding Author:}

Jose Alfredo Palacio-Fernández

Department of Electronic, Institución Universitaria Pascual Bravo

Calle 73 No. 73A-226, Medellín, Colombia

Email: josealpa@pascualbravo.edu.co

\section{INTRODUCTION}

Different battery technologies are currently used in today's implementations, which include the following: sodium sulfur batteries (NaS), redox flow batteries, lithium-ion, lead-acid batteries, and nickel iron [1]. The different reactions and materials of the batteries, regardless of their nature, give rise to different mathematical models, electrochemical circuits [2]-[5]. This allows batteries to be characterized according to different levels of energy demand, which make it possible to permanently monitor the charge capacity and its wear level. Circuit models can be characterized by the union of voltage sources and resistance circuits and capacitors (RC) according to battery dynamics of charge and discharge.

First-order models are generally insufficient to describe battery dynamic behavior, but second-order models can produce voltage responses that closely match actual experimental responses. Third order or higher order models may further reduce the root mean square error, but the parameters are too sensitive to noise and measurement error [6]. Open circuit voltage (OCV) and state of charge (SOC) are key battery parameters [7]. There is a strong non-linear relationship between OCV and SOC in lithium batteries [8].

An accurate battery model is ideal to obtain values close to the batteries' inherent characteristics [9]. Equivalent circuit models are widely used due to their relatively simple mathematical structure and small computational requirement. The model is simple, clear in physical meaning, and can be used to simulate 
battery charge and discharge characteristics [2]. The accurately established battery model is critical for estimating its SOC.

Today, commonly used equivalent battery circuit models include the internal resistance model, the Thevenin model from a first-order RC circuit widely used in lithium batteries [10]-[13]. Or of higher order, as studied by Lai et al. [9], and in lithium or lead acid batteries, as studied by Aurilio et al. [14] and Devarakonda and $\mathrm{Hu}$ [6], and in Hidalgo-Leon et al. [15]. Have used the method of extracting parameters in the time domain to obtain the estimated values of the resistances and capacitors in an equivalent second-order system.

Rapid identification of impedance and OCV parameters can be performed based on charge and discharge curves, which is an effective method for $\mathrm{SOH}$ development [16]. In the model, the main parameters are R0, R, and C. Since these parameters depend on the states of charge/discharge, current, temperature, and SOC, they must be recursive as conditions change. There are many methods for recursive adaptation of parameters such as a neural network, Kalman filter and adaptive filter [17]. SOC determination must take state of health (SOH) into account, since the actual charge value in the current count differs between a $100 \%$ battery and an aged battery [18]

The parameters that characterize battery behavior from circuit models are obtained by means of a current excitation as input and output response in voltage according to SOC. Thus, this current excitation can be arbitrary [6], [18] or specific-size pulses that can deliver the discharge values such as those in Figure 1 [2]. In this type of study, the parameters of battery internal resistance due to the abrupt change of the BC segment are analyzed as shown in Figure 1, as well as the dynamic values defined by the DC and EF sector dependent on the branches of resistors and capacitors in parallel as shown in Figure 2, adapted from [14] and proposed as a second order model in [19], [20].

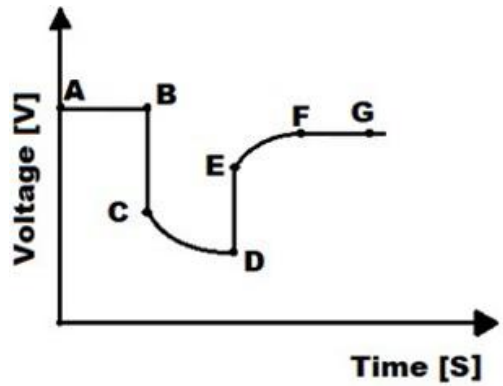

Figure 1. Pulse download image adapted from [2]

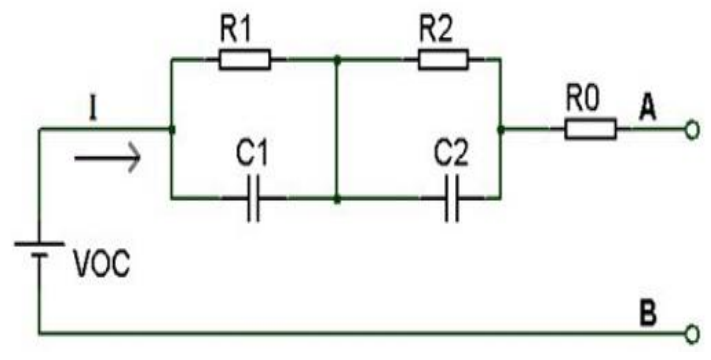

Figure 2. Second order circuit model for some batteries

The coulomb count (Ah) method can be easily performed for online SOC measurements but, due to the accumulation of measurement errors, particularly with inaccurate SOC estimates of the initial battery, precise estimation is still difficult [21]. To eliminate the error of the information provided by the sensor, a Kalman 1D filter can be used, such as the one used by Botero et al. [22], who using a Kalman filter based on the (1), (2), and (3), reduced the noise in an accelerometer in a controlled mobile system with Gaussian noise, Kalman filter serves as a frequency damper due to noise that can be used to smooth the signal readings [23]. The Kalman filter is a mathematical technique that provides an efficient recursive means to estimate the states of a process in such a way that it minimizes the root mean square error [23], [24].

$$
\begin{aligned}
& P_{k}=\frac{P_{k}}{P_{k}+R} \\
& \hat{X}_{k}=\hat{X}_{k-1}+K_{k}\left(Z_{k}-\hat{X}_{k-1}\right) \\
& P_{k}=\left(1-K_{k}\right) P_{k-1}
\end{aligned}
$$

The current expected value $\hat{X}$ (estimated measure) and (covariance of process), depends on the expected value in the previous state and the measured value. This indicates that the measured value has a noise component that differs slightly from the real value and, therefore, an estimated value is made, adding the Kalman constant. It depends on the value of the covariance of process $P$, the error of the covariance of the observation $\mathrm{R}$, obtained from the static process in the case of the acceleration sensor [22]. In general, the Kalman filter is a mathematical procedure that operates by means of a prediction and correction mechanism. 
This algorithm predicts the new state of the system from its previous estimate, adding a correction term proportional to the prediction error in such a way that the latter is statistically minimized [25].

In this case, the Kalman filter was applied to soften the output voltage signals of a lead-acid battery that is discharged by an electronic charge at a rate of $4 \mathrm{Ah}$ for a battery with $\mathrm{SOH}(70 \%)$. The Kalman filter is applied using the measurement noise from the voltage sensor as well as the noise from the current signal. These noises are independent due to the nature of the sensor. The average temperature during the discharge process was $26^{\circ} \mathrm{C}$. A model is obtained by approximating parameters using a lookup table for 29 SOC values for both the original and the filtered data and with the same initial conditions, obtaining greater similarity between the filtered data modeled and the original data than with the original data modeled with its unmodeled equivalent. To adjust the value of the consumption or discharge current, an electronic load such as the one developed in [26] is used, to determine the characteristics of a solar panel, this idea can also be used to adjust the consumption of a battery to a certain value in an experimental process [27]. Improvements in the estimation of the Kalman model are achieved by using a filter that considers system and sensor noise, since the modeled and filtered signal is closer to the original signal than the unfiltered modeled signal.

\section{RESEARCH METHOD}

To obtain the battery model, a system that controls battery discharge is required, another that acquires the signal by hardware, a system that allows filtering the signal, and another to find the parameters that identify the battery (through a software). Each of these stages is described.

\subsection{Electronic upload and variable acquisition}

The developed electronic charge allows maintaining an approximately constant battery discharge current, and it is the input parameter that will be taken into account in the model. Despite having an approximately constant current, the electronic charge developed for this investigation as shown in Figure 3 depends on ambient temperature, which is why a ventilation system was used to keep the temperature approximately stable for a constant current. The temperature ranged from $25-27^{\circ} \mathrm{C}$. Even so, there were small fluctuations that appear as measurement noise due to the environment and the sensor itself, which is one of the parameters to take into account to be filtered before modeling the output signal on the loaded voltage. The elements that increase the temperature as current is demanded from the battery are mainly the insulated-gate bipolar transistor (IGBT) and the power resistor marked at 1 as shown in Figure 3. Number 2 is the analog comparison stage by means of operational amplification and the connection to the control system. Number 3 is the thermal dissipation system through the use of an aluminum heatsink and ventilation to maintain a maximum temperature of $40{ }^{\circ} \mathrm{C}$. The acquisition of voltage and current as shown in Figure 4 is carried out by means of a data acquisition card using Arduino Nano as a control system and peripheral elements of voltage adaptation, current sensors, real-time clock, and storage system using micro memory SD.

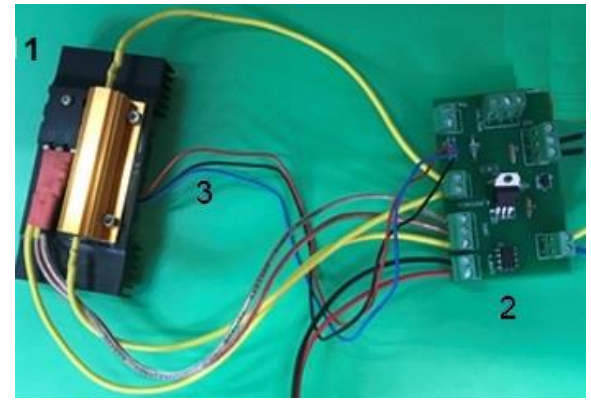

Figure 3. Electronic voltage

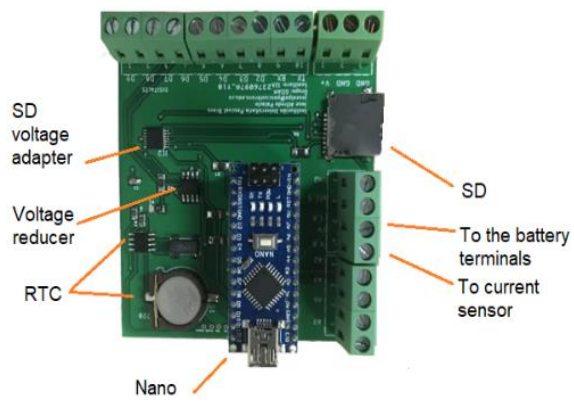

Figure 4. Data acquisition system

\subsection{Data filtering and battery modeling}

Taking into account that the voltage signal at a constant test current used to determine $R_{-} v c$ was approximately Gaussian as shown in Figure 5, the data was filtered using the 1D Kalman filter. It follows the algorithm of Figure 6 , Where $\hat{X}_{k}$ is the actual estimated measure, $R$ is the heat of the variance of the measured data, $P$ is the process covariance, $R_{-} v c$ is the variance of a constant test current modified for Kalman filter, with respect to the original algorithm. The electronic load was configured to deliver a constant current of approximately 4 Amps, new_signal is the vector that stores the initial data to model. 


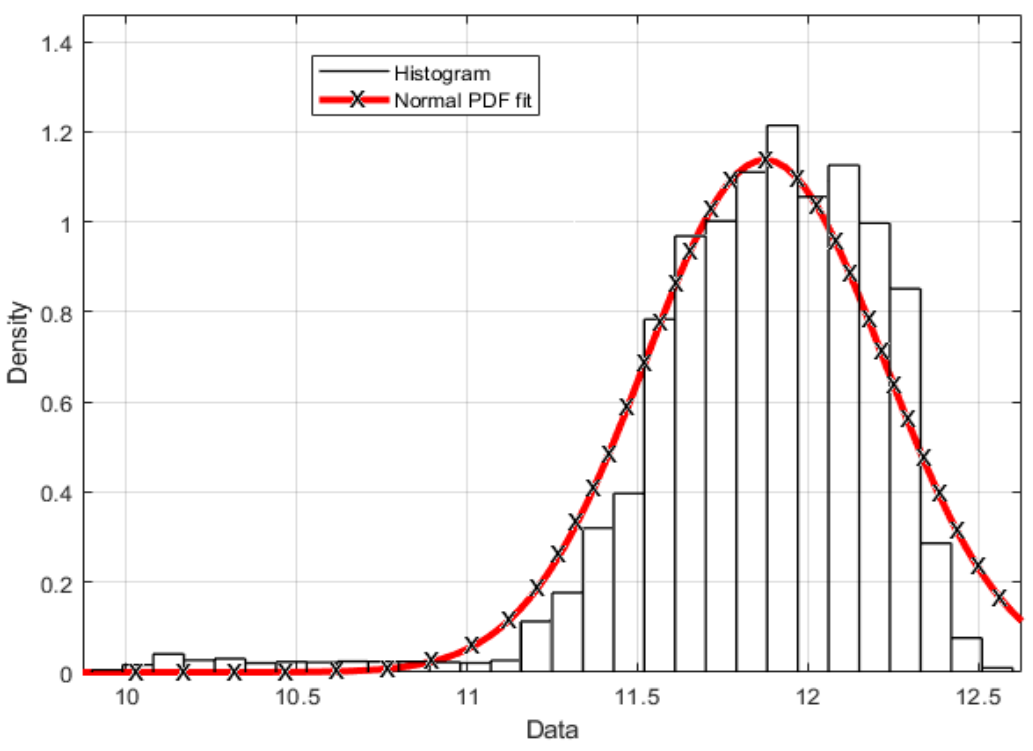

Figure 5. Frequency histogram of the voltage obtained by the test current

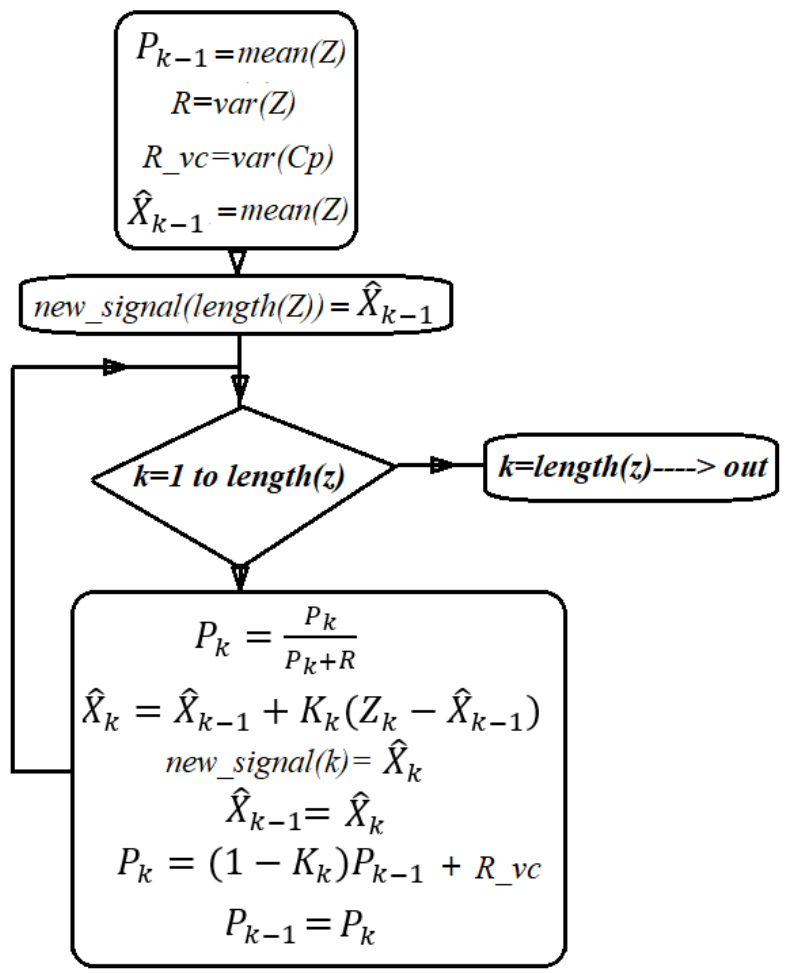

Figure 6. Kalman filtering sequence

Filtered and unfiltered data was modeled using the second-order structure as in Figure 2, which is implicit in a Simulink ${ }^{\circledR}$ block which supports lookup table data for different battery discharge states. SOC were 29 from full charge to almost total discharge of the battery using the acquisition system and electronic charging. The Simulink ${ }^{\circledR}$ system as shown in Figure 7 compares the output data with adjusted values according to the input current of the voltage values $\mathrm{V}_{\mathrm{oc}}, \mathrm{R} 0, \mathrm{R} 1, \mathrm{R} 2, \mathrm{C} 1$ and $\mathrm{C} 2$ through the application of parameter estimation, from the solution of (4). Figure 8 shows the voltage signal for the arbitrary initial parameters of $\mathrm{V}_{\mathrm{oc}}$ and $\mathrm{R} 0, \mathrm{R} 1, \mathrm{R} 2, \mathrm{C} 1$, and $\mathrm{C} 2$, and the desired curve in this case. In this case, the data to which the Kalman filter was applied is represented. 
$V_{\text {batt }}=V_{O C}-I R_{1}\left[1-e^{\left(-\frac{t}{\tau 1}\right)}\right]-I R_{2}\left[1-e^{\left(-\frac{t}{\tau 2}\right)}\right]-I R_{0}$

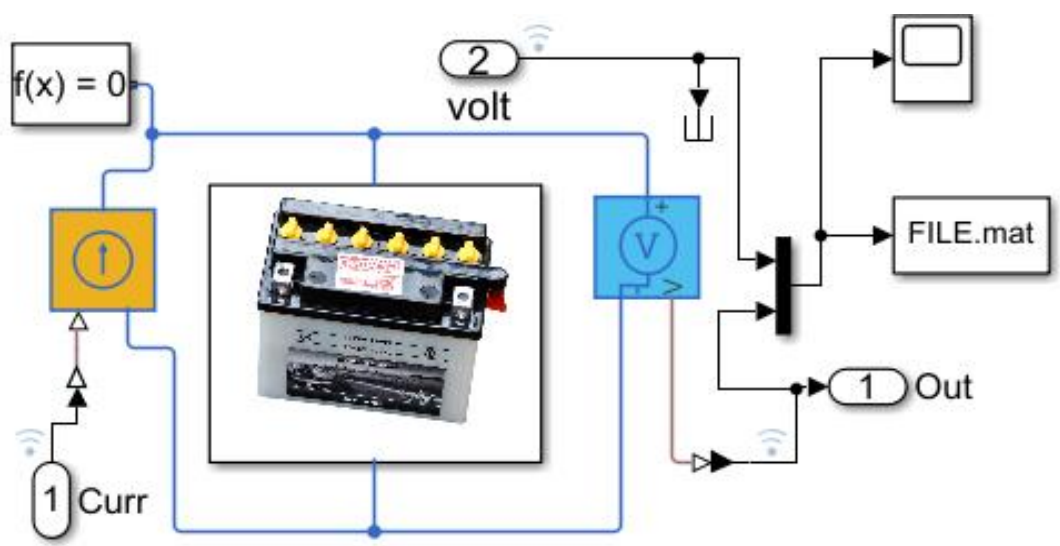

Figure 7. Scheme in Simulink® to identify the parameters

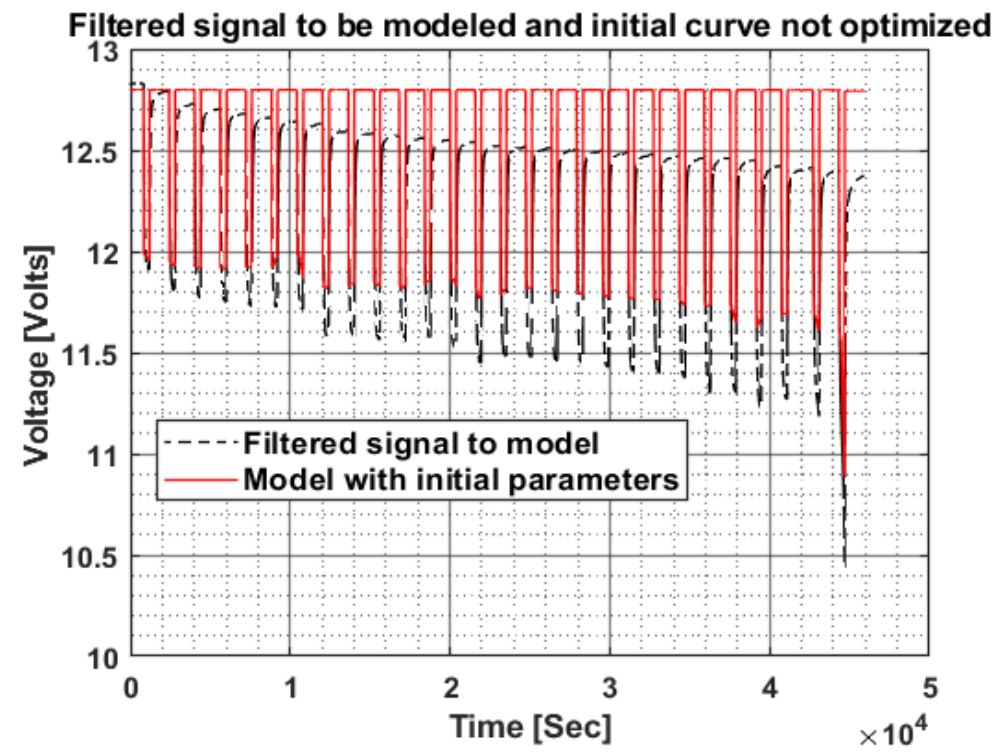

Figure 8. Curve to model and curve for initial parameters (red)

\section{RESULTS AND DISCUSSION}

The parameter obtaining system carried out using Simulink ${ }^{\circledR}$ is a long process dependent on the processor and the choice of the initial parameters. In this case, the determination of the parameters took 12 hours for the model of the unfiltered signal and 9 hours for the filtered signal. It must be affirmed that the initial conditions or parameters were the same when the two models were run.

After determining the parameters for each SOC, the values of $\mathrm{R}, \mathrm{C}$, and $\mathrm{V}_{\mathrm{oc}}$ were found, similar to the values of the filtered signal and its respective model. Figure 9 shows the model curves of the filtered data and the original filtered data in the last two SOCs. The concordance of the curves and the change in concavity of both can be seen, indicating that the second-order model was adequate, even if it is more noticeable in the last two steps for discharge than for this case, which was 4A. The data were also modeled based on the unfiltered signal, noting that the model of the filtered signal on the black curve in Figure 10 is closer to the original signal (red curve) than the same unfiltered model (green curve). When the battery discharge is interrupted, it returns to the $\mathrm{V}_{\mathrm{oc}}$ as shown in Figure 11, a better approximation to the original signal for the filtered signal model. The initial conditions for the unfiltered signal model may have fallen to a 
local maximum value of optimization and, therefore, it may not be able to better identify the signal compared to the filtered signal.

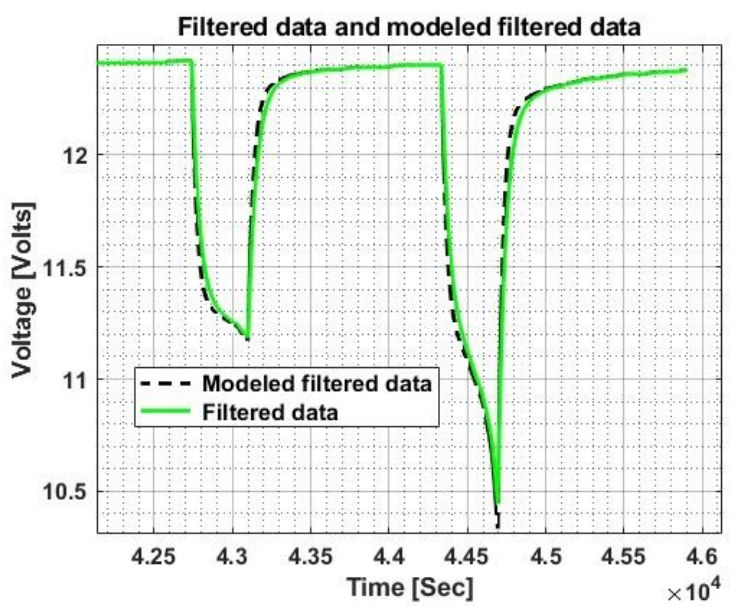

Figure 9. Last two download sectors comparing filtered signal and filtered-modeled signal

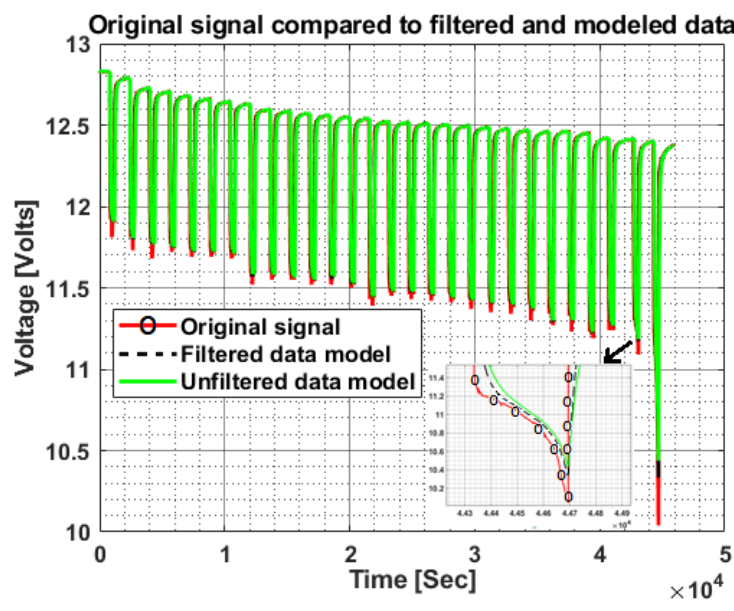

Figure 10. Comparative original, filtered patterned and patterned unfiltered signal

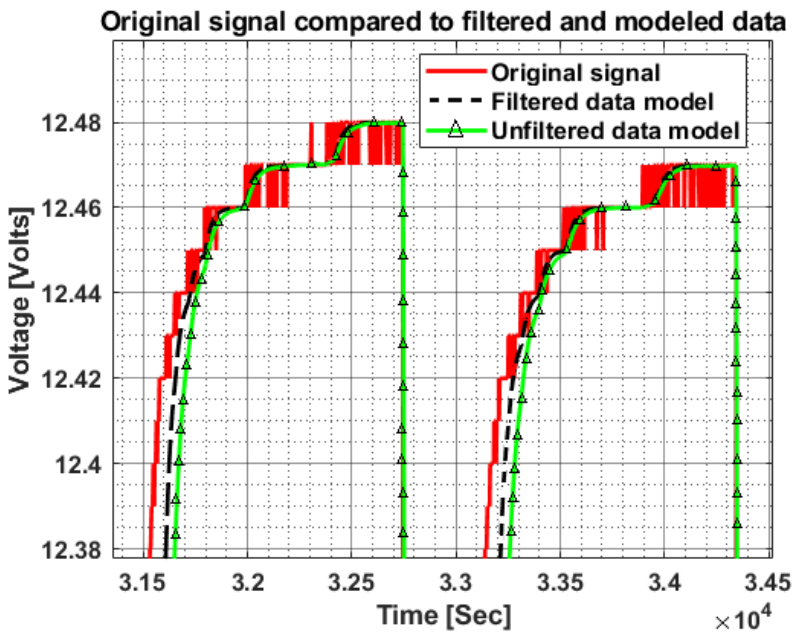

Figure 11. Comparative original, filtered modeled and unfiltered patterned signal on return to $\mathrm{V}_{\mathrm{oc}}$

\section{CONCLUSION}

The process of obtaining parameters is quite long, requiring higher speed processors and even more so if the expectation is to model with an order system greater than two. An option that was not considered in this article is obtaining parameters through parallel programming, a resource present in the used software. Although the Kalman filter used was adjusted to the original data, the additive noise to the covariance $\mathrm{P}\left(R_{-} v c\right)$ is still an empirical method that can be validated in future investigations. While the patterned filtered signal approaches the original signal, it may have been even closer if the gap at the end due to the Kalman filter was considered.

\section{ACKNOWLEDGEMENT}

This work is supported by the Sapiencia (Agencia de Educación Superior de Medellín) with the Intermediation of the Institución Universitaria Pascual Bravo that manages the resources of doctoral studies of several of its teachers. Resources have also been obtained from the TESLA group at the University of Antioquia. 


\section{REFERENCES}

[1] R. H. Leon et al., "A survey of battery energy storage system (BESS), applications and environmental impacts in power systems," in 2017 IEEE Second Ecuador Technical Chapters Meeting (ETCM), Oct. 2017, pp. 1-6, doi: 10.1109/ETCM.2017.8247485.

[2] Z. Chen, L. Yang, X. Zhao, Y. Wang, and Z. He, "Online state of charge estimation of Li-ion battery based on an improved unscented Kalman filter approach," Applied Mathematical Modelling, vol. 70, pp. 532-544, Jun. 2019, doi: 10.1016/j.apm.2019.01.031.

[3] C. Lyu, Q. Lai, T. Ge, H. Yu, L. Wang, and N. Ma, "A lead-acid battery's remaining useful life prediction by using electrochemical model in the particle filtering framework," Energy, vol. 120, pp. 975-984, Feb. 2017, doi: 10.1016/j.energy.2016.12.004.

[4] C. Weng, J. Sun, and H. Peng, "A unified open-circuit-voltage model of lithium-ion batteries for state-of-charge estimation and state-of-health monitoring," Journal of Power Sources, vol. 258, pp. 228-237, Jul. 2014, doi: 10.1016/j.jpowsour.2014.02.026.

[5] H. Pan, Z. Lü, W. Lin, J. Li, and L. Chen, "State of charge estimation of lithium-ion batteries using a grey extended Kalman filter and a novel open-circuit voltage model," Energy, vol. 138, pp. 764-775, Nov. 2017, doi: 10.1016/j.energy.2017.07.099.

[6] L. Devarakonda and T. Hu, "Effects of rest time on discharge response and equivalent circuit model for a lead-acid battery," Journal of Power Sources, vol. 282, pp. 19-27, May 2015, doi: 10.1016/j.jpowsour.2015.02.030.

[7] Y. Boujoudar, H. Elmoussaoui, and T. Lamhamdi, "Lithium-Ion batteries modeling and state of charge estimation using artificial neural network," International Journal of Electrical and Computer Engineering (IJECE), vol. 9, no. 5, pp. 3415-3422, Oct. 2019, doi: 10.11591/ijece.v9i5.pp3415-3422.

[8] Q. Zhang, N. Cui, Y. Li, B. Duan, and C. Zhang, "Fractional calculus based modeling of open circuit voltage of lithium-ion batteries for electric vehicles," Journal of Energy Storage, vol. 27, Feb. 2020, Art. no. 100945, doi: 10.1016/j.est.2019.100945.

[9] X. Lai, S. Wang, S. Ma, J. Xie, and Y. Zheng, "Parameter sensitivity analysis and simplification of equivalent circuit model for the state of charge of lithium-ion batteries," Electrochimica Acta, vol. 330, Jan. 2020, Art. no. 135239, doi: 10.1016/j.electacta.2019.135239.

[10] X. Dang, L. Yan, H. Jiang, X. Wu, and H. Sun, "Open-circuit voltage-based state of charge estimation of lithium-ion power battery by combining controlled auto-regressive and moving average modeling with feedforward-feedback compensation method," International Journal of Electrical Power \& Energy Systems, vol. 90, pp. 27-36, Sep. 2017, doi: 10.1016/j.ijepes.2017.01.013.

[11] X. Yu, J. Wei, G. Dong, Z. Chen, and C. Zhang, "State-of-charge estimation approach of lithium-ion batteries using an improved extended Kalman filter,” Energy Procedia, vol. 158, pp. 5097-5102, Feb. 2019, doi: 10.1016/j.egypro.2019.01.691.

[12] H. Wu, S. Yuan, X. Zhang, C. Yin, and X. Ma, "Model parameter estimation approach based on incremental analysis for lithiumion batteries without using open circuit voltage," Journal of Power Sources, vol. 287, pp. 108-118, Aug. 2015, doi: 10.1016/j.jpowsour.2015.04.037.

[13] J. Jiang, Y. Liang, Q. Ju, L. Zhang, W. Zhang, and C. Zhang, “An equivalent circuit model for lithium-sulfur batteries,” Energy Procedia, vol. 105, pp. 3533-3538, May 2017, doi: 10.1016/j.egypro.2017.03.810.

[14] G. Aurilio et al., "A battery equivalent-circuit model and an advanced technique for parameter estimation," in 2015 IEEE International Instrumentation and Measurement Technology Conference (I2MTC) Proceedings, May 2015, pp. 1705-1710, doi: 10.1109/I2MTC.2015.7151537.

[15] R. Hidalgo-Leon et al., "Modeling battery under discharge using improved thevenin-shepherd electrical battery model," in 2018 IEEE Vehicle Power and Propulsion Conference (VPPC), Aug. 2018, pp. 1-5, doi: 10.1109/VPPC.2018.8604958.

[16] Y. Cui et al., "State of health diagnosis model for lithium ion batteries based on real-time impedance and open circuit voltage parameters identification method," Energy, vol. 144, pp. 647-656, Feb. 2018, doi: 10.1016/j.energy.2017.12.033.

[17] S. Cho, H. Jeong, C. Han, S. Jin, J. H. Lim, and J. Oh, "State-of-charge estimation for lithium-ion batteries under various operating conditions using an equivalent circuit model," Computers \& Chemical Engineering, vol. 41, pp. 1-9, Jun. 2012, doi: 10.1016/j.compchemeng.2012.02.003.

[18] M. Cacciato, G. Nobile, G. Scarcella, and G. Scelba, "Real-time model-based estimation of SOC and SOH for energy storage systems," in 2015 IEEE 6th International Symposium on Power Electronics for Distributed Generation Systems (PEDG), Jun. 2015, pp. 1-8, doi: 10.1109/PEDG.2015.7223028.

[19] M. Souaihia, B. Belmadani, and R. Taleb, "A robust state of charge estimation for multiple models of lead acid battery using adaptive extended Kalman filter," Bulletin of Electrical Engineering and Informatics (BEEI), vol. 9, no. 1, pp. 1-11, Feb. 2020, doi: 10.11591/eei.v9i1.1486.

[20] B. V. Rajanna and M. Kiran Kumar, "Dynamic model development for lead acid storage battery," Indonesian Journal of Electrical Engineering and Computer Science (IJEECS), vol. 15, no. 2, pp. 609-619, Aug. 2019, doi: 10.11591/ijeecs.v15.i2.pp609-619.

[21] F. Claude, M. Becherif, and H. S. Ramadan, "Experimental validation for Li-ion battery modeling using Extended Kalman Filters," International Journal of Hydrogen Energy, vol. 42, no. 40, pp. 25509-25517, Oct. 2017, doi: 10.1016/j.ijhydene.2017.01.123.

[22] J.-S. Botero V, W. Hernández, and E. Fernández, "Orientation of a triaxial accelerometer using a homogeneous transformation matrix and Kalman filters," International Journal on Smart Sensing and Intelligent Systems, vol. 7, no. 4, pp. 1631-1646, Dec. 2014, doi: 10.21307/ijssis-2017-724.

[23] W. Djuriatno, E. Maulana, H. Hasan, E. D. Arisandi, and W. Wijono, "Velocity measurement based on inertial measuring unit," TELKOMNIKA (Telecommunication Computing Electronics and Control), vol. 17, no. 4, pp. 1898-1906, Aug. 2019, doi: 10.12928/telkomnika.v17i4.11826.

[24] R. Xiong, H. He, F. Sun, and K. Zhao, "Evaluation on state of charge estimation of batteries with adaptive extended kalman filter by experiment approach," IEEE Transactions on Vehicular Technology, vol. 62, no. 1, pp. 108-117, Jan. 2013, doi: 10.1109/TVT.2012.2222684

[25] A. Florián, "Performance comparison of state observers in linear systems through the application to a continuous current motor," Revista CINTEX, vol. 23, no. 1, pp. 51-59, Oct. 2018, doi: 10.33131/24222208.310.

[26] A. A. Willoughby and M. O. Osinowo, "Development of an electronic load I-V curve tracer to investigate the impact of Harmattan aerosol loading on PV module pern2tkformance in southwest Nigeria," Solar Energy, vol. 166, pp. 171-180, May 2018, doi: 10.1016/j.solener.2018.03.047.

[27] Z. Xia, J. A. A. Qahouq, E. Phillips, and R. Gentry, "A simple and upgradable autonomous battery aging evaluation and test system with capacity fading and AC impedance spectroscopy measurement," in 2017 IEEE Applied Power Electronics Conference and Exposition (APEC), Mar. 2017, pp. 951-958, doi: 10.1109/APEC.2017.7930811. 


\section{BIOGRAPHIES OF AUTHORS}

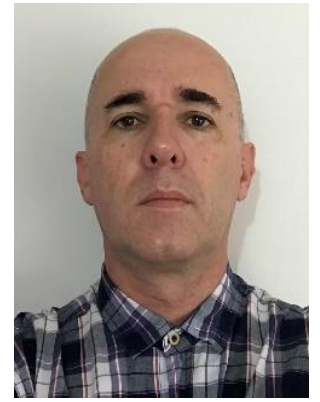

Jose Alfredo Palacio-Fernández (D) SII SC P Electronic Engineer from Universidad de Antioquia in 2002, he received his Master in automation and industrial control 2012 from Instituto Tecnológico Metropolitano de Medellín. At present, he is Ph.D. (c) in Environmental Engineering focused on renewable energy. His research interests include: power electronics, artificial intelligence and automation and control. $\mathrm{He}$ is a junior researcher in Colciencias and member of the Research Group GIIAM, at Institución Universitaria Pascual Bravo and TESLA at Universidad de Antioquia. He can be contacted at email: josealpa@pascualbravo.edu.co.

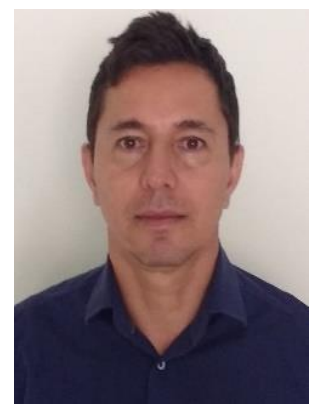

Edwin Garcia Quintero (iD) SC SC Electrical Engineer from Universidad Industrial de Santander (Colombia) in 2000, he received his Research Aptitude (Master) in Electrical Technology from Universidad Politécnica de Valencia (Spain) in 2004 and received his Doctorate in Electrical Technology, Generation, Transmission and Distribution from Universidad Politecnica de Valencia (Spain) in 2008. He is an associate professor of Universidad de Antioquia (Colombia). His research interests include: renewable energy, energy storage, energy efficiency. He is associate researcher in Colciencias and manager of the Research Group TESLA, at Universidad de Antioquia. He can be contacted at email: edwin.garciaq@udea.edu.co. 